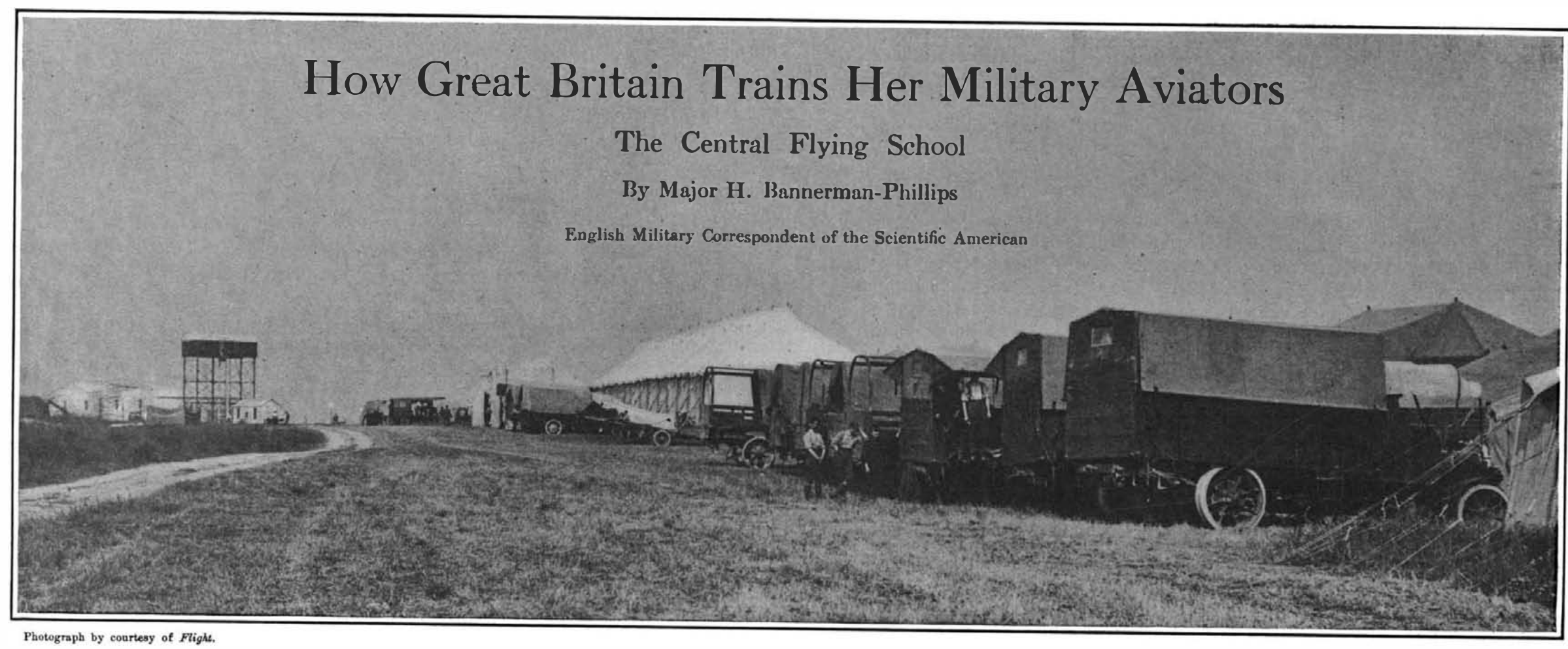

A general view of the hangars at Upavon, on Salisbury Plain, England.

THE Central Flying School at Upavon, on Salisbury 1 Plain, is a very important part of the organization for military aviation in that it is intended as a center of instruction for both the naval and military services. That it was in the nature of an experiment goes without saying, but its success has justified its inception, thanks to the personality of the officers who were placed in charge of it from the first. The situation is open and notoriously windy, a circumstance which, in contradistinction to many otherwise preferable, and from the point of view of tractive, flying grounds on the conti and elsewhere, affords a more suitable area for training men who will be expected to go out in practically all weathers, actically all weathers according to the exigencies of the service.

The buildings devoted to aeronautics number about sixteen sheds of different capacities, offices, lecture rooms, repair shops, and a department of meteorology, but the government has also a l rea dy commenced the erection of permanent buildings, including quarters for the permanent staff offief thirteen, with four assistthirteen, with four assistant instructors, two from Army, with a large permanent staff of mechanics. The school is organized for instruction in four flights, in each of which the machines are of one type at present, but pupils are shifted and changed about from one flight to another in accordance with their proficiency, in order that they may acquire a knowledge of al the types used in the air services. Flying b e gi n s with the dawn, say at $3: 30$ A. M. or 4 A. M., and goes on till about 8 A. M. After that work is performed in the workshops and sheds until noon, followed by a lecture before the midday meal. Two hours rest is allowed in the afternoon in view of the necessity for in view of the necessity for and from 5 P. M. to dusk flying goes on once more. Physically and mentally it is distinctly a strenuous life, but healthy.

During the month of June there was a special concentration camp for air men at Netheravon, whic . Phoograph by courtesy of Flight. was attended by five squadrons of military aeroplanes coming from all parts of the country, besides the Kite Section, the Aircraft Park, and the various headquarters aeroplanes. Altogether seventy machines were available.

The move of the squadron stationed at Montrose was

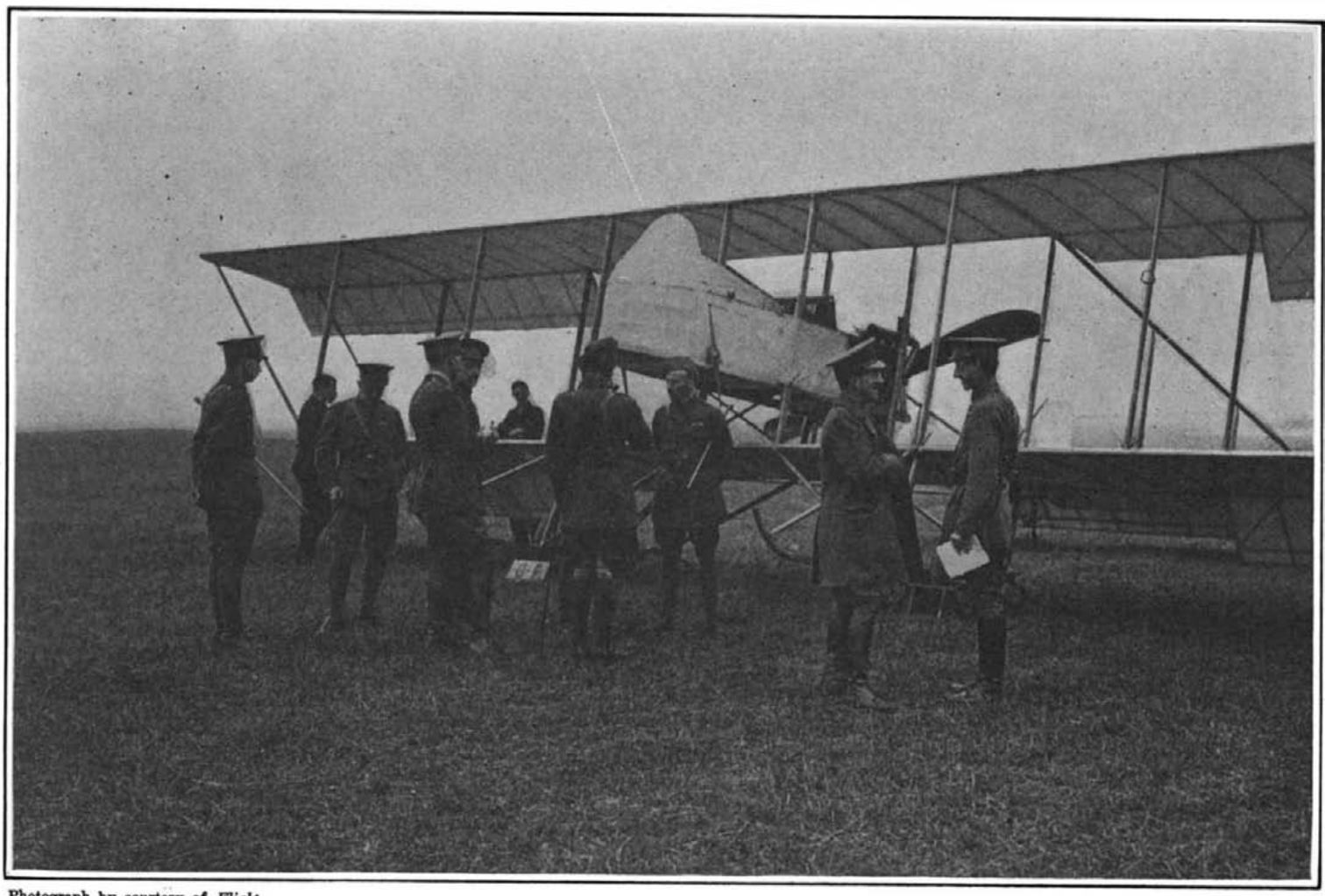

A group of pupils with their instructors.

made the occasion of a test march across country under active service conditions, keeping in touch with the transport-a very different matter to the mere concentration of aeroplanes from various stations by way of the air alone, without the hampering condition of having to be met by their transport at the end of each day's journey, like the movement which was so brilliantly carried out not long ago by the German air service. The scheme of the Montrose squadron involved daily flights on the part of the machines of only 80 to (their motor transport had

to meet them in camp at to meet them in camp a the end of each day, carrybe required for upkeep and repairs. The $\mathrm{transport}$ train included no less than twenty-three motor vehicles of all sorts, and traveling at intervals of 200 yards, they covered about two and one half miles of road while in progress, and had to move a distance of 600 $\mathrm{m}$ iles between Montrose and Netheravon, and as their freight included spare parts for every one of the twelve aeroplanes of the squadron and four spare engines, it may be realized that it was not light. $\mathrm{Al}$ though there was a regrettable and fatal disaster, through fog, at Northallerton, when two officers unfortunately lost their lives on duty, the journey, as a whole, was successful and instructive. Normally each squadron of military aeroplanes has a strength of 19 officers, 2 warrant officers, 21 sergeants, and 115 $\mathrm{rank}$ and file, and requires a transport train of 38 vehicles, and the transport for such an assemblage of aircraft which encamped at Netheravon this year would include 42 light moto ir lories 18 shed reserve equipment lorries, altogether a total of 228 vehicles, which if spaced at 200 yards while on the march, w o u ld cover 26 miles of roadway.

The work of the Concentration Camp opened on June 2nd with a confer ence of all officers, at which the commanding of ficer explained briefly the objects of the camp, viz. to test in various ways the degree of training of the "personnel" both on the ground and in the air, the work and handling of aircraft and transports and experiments of numerous sorts; also the study and co-ordination by means of lectures, discussions, conferences, and specially de- 
tailed committees, of the innumerable problems, such as mobilization, technical and military training, observation, including observation of artillery fire, workshops, stores, meteorology, wireless telegraphy, photography, bomb-dropping, and organization of all kinds, which are essential to the building up of an air service for military purposes on a firm and efficient basis.

Although seventy machines were available, it was obvious that flying and the carrying out of tests with aircraft was only one phase of the instruction carried out, as will be seen from the brief notes of the work accomplished, and it will be readily understood that the results of tests could not in many cases be made public, for reasons of military expediency.

During the first week the weather was anything but favorable and very disappointing, considering the time of year. Heavy rain and hail swept over the Wiltshire Downs, followed by slight frost, and a bitter northeast wind of 30 miles an hour, and gusty at that. A scheme of maneuvers was set by the Camp Commandant for the first day, which was primarily intended to test the value of reconnaissance from aircraft of troops stationary on the battlefield. The hostile troops were represented by the individual transport motorcyclists and men of the Royal Flying Corps, who were dispatched early in the morning with confidential instructions to take up positions and remain stationary, principally at cross-roads, within the area covered by the operations, and keep time till $1 \mathrm{P}$. M.; these positions were, of course, kept secret from the reconnoitering officers who were sent off later in the day and allowed one and one half hours in which to observe and make notes, on the understanding that they were to keep their machines at an altitude of not less than 2,500 feet. Each aeroplane carried a pilot and observer, and the latter was provided with a map of the theater of operations, and had to make his notes in the air and hand in his report immediately on return to camp. The results were not published, but are understood to have been satisfactory, and the pilots managed their machines exceptionally well in face of the very gusty wind. During this week the demonstrations of rigging and tuning up of aeroplanes which took place from time to time, for the special benefit of the rank and file of the Royal Flying Corps, were found to be very instructive from a practical point of view.

Observation of artillery practice was carried on during the second week, together with other work of an experimental nature, of which the results were not made public; speed tests, climbing and landing test were carried out, the latter.including flying by night and landing by the light of special flares.

It is recognized that since a military aviator may frequently have to land in an unknown part of a foreign country and get away again, and even during maneuvers in his own country can never be certain where he may have to come down, the power of landing with safety is one of the most important parts of his training, and is studied accordingly, both as regards choosing at a rapid glance around the best available landing place, and making the best landing practicable under unfavorable circumstances.

On June 30th the aircraft exercises consisted of aeroplanes searching for a disabled aircraft, represented by a balloon, which ascended from a point unknown to the searchers, some thirty miles from the Concentration Camp. The altitude of the balloon varied from 2,000 to 5,000 feet, and as the day was hazy, it could only be seen from a distance of eight miles at the farthest; nevertheless it was found by 50 per cent of the aeria scouts who were sent up in the aeroplanes to look for it.

Throughout the whole period of the month in camp the reconnaissance tests and practice were continuous and progressive, as was only natural, seeing that observation of the enemy's movements and dispositions is the end and aim to which all else connected with military aviation is subsidiary, and there can be no doubt that the combined training of all ranks and the opportunities for conference, exchange of ideas and mutual instruction, in addition to listening to lectures and discussions on various topies, were of the utmost advantage to all who took part in this first Concentration Camp for Aircraft in Great Britain.

\section{The Canadian Arctic Expedition}

A CCORDING to information received in Toront A seltember 1st, Stefansson, the leader of the Canadian Arctic Expedition, set out from Martin Point, northern Alaska, on March 22nd, last for a sledge jour ney northward over the sea ice. After sending back a supporting party at the edge of the continental shelf, in latitude 70 degrees 20 minutes, longitude 140 degrees 30 minutes west, the leader proceeded with two men one sled, six dogs, two rifles, and plenty of ammunition. He expected to turn back at the end of fifteen days, but thought he might be driven by winds and currents to Banks Land. Nothing, however, has since been hear of him, though two vessels have cruised along the coast of Banks Land in search of him. The southern section of the expedition, under Dr. Anderson, left Herschel
Island about August 17th for Coronation Gulf, where explorations will be carried on in accordance with the original programme. A dispatch from Nome, date September 1st, announced that the revenue cutter "Bear" had failed in its attempt to reach Wrangel Island, where Stefánsson's northern party took refuge ast season after the loss of the "Karluk." The "Bear" was within 20 miles of the island on August 21st, but after fighting ice and storms for six days was forced to return to Nome for coal and provisions. She is now engaged in another attempt. The former revenue cutter "Corwin" has been fitted out by miners at Nom and has sailed on a similar errand of relief. Meanwhile the hope is still cherished that the Russian icebreakers "Taimyr" and "Vaigatch," which are makin their third annual cruise in the Arctic, may succeed in bringing off the marooned explorers.

\section{German Men of Science and the British Association}

A MONG the party which proceeded to Australia to $\mathbf{A}_{\text {attend the meeting of the British Association were }}$ a number of distinguished German men of science, who, in most cases were accompanied by their wives, daughters, or sons. Germany's war with Great Britain has necessarily placed these scientists in a position of difficulty, since they are subject to the orders of the Commonwealth military authorities, as regards departure from Australia, and even in that event, their destination must be a matter for official cognizance and settlement. Perhaps the most popularly known men are Dr. A. Penck, professor of geography in the University of Berlin; Dr. F. von Luschan, professor of anthropology in the same university; and Dr. J. Walther, professor of geology and palæontology in the Universit of Halle. Included also among the visitors were a number of American, Russian, and Danish scientists.

It is possible that the temporary hospitality of America, a non-belligerent power, may prove a way out of the grave situation that has arisen, one unique in the annals of science, and of unforgettable character.

For the information of our readers we append a lis of American scientists who accepted the invitation of the British Association to its Australian meeting

Mr. C. G. Abbot, director Smithsonian Astrophysic Observatory, Washington.

Mr. Z. Baber, professor of geography and geology, University of Chicago.

Mr. F. Baker, Scripps Institution for Biological Reearch, San Diego, Cal.

Dr. Lyman J. Briggs, Department of Agriculture, Washington.

Dr. R. T. Chamberlin, Geological Department, Uniersity of Chicago.

Dr. E. G. Conklin, professor of zoology, Universit Princeton.

Dr. C. B. Davenport, director Department of Exper mental Evolution, Cold Spring Harbor, Long Island.

Prof. W. M. Davis, Harvard University.

Dr. G. A. Dorsey, curator of anthropology, Field Museum of Natural History, Chicago.

Mr. C. F. McClure, Department of Comparative Antomy, Princeton University.

Mr. E. S. Moore, professor of geology and mineralogy, School of Mines, Pennsylvania State College.

Prof. Ira Remsen, Johns Hopkins University, Balti-

Dr. H. C. White, professor of chemistry, University of Georgia.

Dr. W. M. Wheeler, professor of economic entomology, Harvard University.

\section{War Issue Number 2 of the Scientific American}

THE September 5th issue of the Scientific American -our War Number-has met with the success that of military men, each an expert in his special field, it met a popular demand for accurate information on the technical aspects of modern warfare, which seems. to be insatiable. Large as the number was and packed with articles and pictures of the most timely character. it could not possibly exhaust the subject. Accordingly, it has been decided to make the next monthly magazine number of the Scientific AMErican-that which will bear the date October 3rd-another war issue, in which subjects will be discussed fully as important as those which were taken up in the September number, but which the limitations of space prevented our considering at all.

We have heard very much, for example, of the turret fort, which was used with such brilliant success at Liege, but which finally succumbed to the enormous siege artillery which the Germans eventually brought to bear. Here we have at once two subjects on which practically nothing has appeared: The modern fixed ortification of steel and concrete, and the means for reducing it. The October 3rd issue of the Scientific American will, therefore, contain an elaborate drawing

and description of the famous Gruson turret, with photographs showing exactly what was the effect of the German siege artillery upon it; and also an article on those marvelous 11-inch siege guns which, by high angle fire, dropped hundreds of pounds of high explosive upon hapless defenders crouching behind their protection and manfully serving their guns to the last. We have heard much, too, of the floating mines with which the Germans have sown the North Sea, and which have proved such a menace to neutral shipping. How are these mines constructed? What is their effect? How does a battleship guard itself against them? These questions will all be taken up in an authoritative way.

The submarine boat, too, will command its share of attention. Sectional views of boats will be published and the interior mechanism of a submarine revealed just as if it were a watch that has been picked apart.

of fortifications in the field much also may be learned from the October 3rd issue of the Scientific American. It is known in a general way to the public that obstacles of every kind are thrown in the way of attacking infantry-barbed wire, felled trees with all their branches and similar barricades. Such obstacles and defenses are thrown up very systematically. The character of the obstacles and the methods of placing them in position will be described and illustrated.

John Barrett, director of the Pan-American Union, was the first to draw the attention of American manufacturers to the trade opportunity which confronts them as a result of the war. The Scientific American has asked him to prepare an article in which the prospects that now tempt the American business man are carefully considered. Letters from prominent financiers, merchants, and manufacturers on the subject will also appear.

\section{A Street Traffic Signal}

$T^{O}$ ease the work of the traffic policeman and afford T a far greater measure of protection to the traveling public, Mr. H. D. Heuer of St. Louis, Mo., has invented a device by means of which the guardians of the traftic will not only be protected from the weather, but will be relieved of the strain of extending their arms and removed from the direct center of traffic. Mr. Heue offers to give his invention to the public. The device is exceedingly simple in construction, and by no means expensive. It consists of an overhead signal or semaphore, operated by a traffic officer who is removed from the direct path of traffic and stationed in or under a shelter house, which is slightly elevated, on the street corner, where he can observe and direct the movement of traffic by operating the signal device and signal bells. He is consequently out of the danger zone himself, and can devote all his thought and energy to minimizing the risk of others. The signal will be suspended from a cable attached to poles located on diagonal corners, and in plain view of pedestrians and vehicle drivers for a long distance.

The signal consists of four semaphore blades, each about 36 inches long, constructed similarly to an electric ceiling fan, two of the blades being colored red, signifying "danger" or "stop," while the other two will be colored white, and will signify "clear" or "go ahead." To render the signals effective by night, electric lamps will be provided for the semaphores, the colors being in accord with the colors of the semaphore blades. The signal is moved 90 degrees in both directions, the attention of the public being called to the change by an electric bell, which is situated on the pole where the traffic guardian is standing.

When the signal is not in use as a guide to traffic the semaphores may be placed diagonally, which would be an indication that the traffic guardian is absent and traffic could proceed under its own control.

\section{The Current Supplement}

I the current issue of the ScIentific American Sup$I_{\text {PLEMENT, No. 2020, of September } 19 \text { th, will be found }}$ a splendidly illustrated article on the Canadian $\mathrm{Al}_{1} \mathrm{~s}$ which introduces a new American playground and scientific storehouse that will be appreciated by all lovers of natural scenery. There is a second installment of Prof Bateson's remarkable address on Heredity, which is being published in full, and every line of which will be read with interest by laymen as well as scientists. A New Application of Roentgen Rays tells about an infallible method of establishing the authenticity of oil paintings, and the detection of forgeries in art. America's Opportunity by a World Catastrophe is an interesting resumé of history, and discusses a matter that is engaging the attention of the whole country. The Industries of Liege tells of its great manufactories and 